\title{
Rhizobacteria Capable of Producing ACC Deaminase Promote Growth of Velvet Bean (Mucuna pruriens) under Water Stress Condition
}

\author{
Aansa R. Saleem ${ }^{1}$, Nazneen Bangash ${ }^{1}$, Tariq Mahmood ${ }^{1}$, Azeem Khalid ${ }^{1 *}$, Mauro Centritto ${ }^{2}$ and M.T. Siddique $^{3}$ \\ ${ }^{1}$ Department of Environmental Sciences, Pir Mehr Ali Shah Arid Agriculture University, Rawalpindi 46300, Pakistan \\ ${ }^{2}$ Trees and Timber Institute, National Research Council, Via Madonna del Piano 10, 50019 Sesto Fiorentino (FI), Italy \\ ${ }^{3}$ Department of Soil Science \& Soil Water Conservation, PMAS Arid Agriculture University, Rawalpindi, Pakistan \\ *For correspondence: azeem@uaar.edu.pk; azeemuaf@yahoo.com
}

\begin{abstract}
Decreased water levels cause severe reduction in growth and yield of plants. Generally the plant growth is inhibited under water stress due to the high concentration of ethylene in the rhizosphere. Plant growth promoting rhizobacteria (PGPR) inhabiting the rhizosphere capable of producing 1-aminocyclopropane-1-carboxylate deaminase (ACCd) enzyme can also reduce the concentration of ethylene in plant by breaking down ACC, the immediate precursor of ethylene. Such PGPR were isolated from different parts of the province of Punjab and Khyber Pakhtunkhwa and screened for their ability to promote growth of velvet bean in axenic conditions. The results showed that some rhizobacterial strains significantly improved the growth of roots and shoots in normal and water stress condition. A significant increase was observed in root length (32\%), shoot length $(110 \%)$, root dry weight $(50 \%)$ and shoot dry weight $(60 \%)$ in response to inoculation compared to an uninoculated control. Four strains showed very encouraging results in promoting the growth of velvet bean. The ability of selected rhizobacteria to reduce the concentration of ethylene was confirmed by performing classical triple response bioassay in etiolated pea seedlings. The results of this study illustrate that ACCd active PGPR can be used for improving plant growth and yield of velvet bean under limited availability of water. (C) 2015 Friends Science Publishers
\end{abstract}

Keywords: Drought; Ethylene; Root growth; PGPR; Inoculation; Velvet bean

\section{Introduction}

Water is an influential abiotic factor in determining plant growth, physiology and crop yield. Climatic changes caused uneven and erratic rainfall in various regions of the world, reducing fresh water availability to critical levels in some areas (Barnaba et al., 2008; Chen et al., 2013). Reduction and irregular rainfall decreases surface soil water available to plants and nutrient transport. Compared to other stresses, drought is a major factor limiting plant growth and yield (Belimov et al., 2008; Lauteri et al., 2014). Moreover, climate change scenarios predict increased intensity and duration of water stress in the future (IPCC, 2007). In Pakistan, the demand for water is expected to grow by a factor of 2.2 by 2050 (Bates et al., 2008).

Increasing world population necessitates the improvement in agricultural practices for more food crop production under drought (Grierson et al., 2011). The characteristics of the plants that confer water absorption are likely to be most vital to mitigate effects of drought (Ren et al., 2007; Centritto et al., 2009; Chaves et al., 2009). Water absorption by the plant is linked to the root system (Bangash et al., 2013). Therefore, recently attention is diverted to improve root system and functioning to enhance water use efficiency, especially high yield with less water (Lynch, 2007; Ghanem et al., 2011; Vacheron et al., 2013).

Under stress condition, plant roots receive stress signals and transport chemical signals to upper part to limit the use of water for maintaining cellular water. Plant roots also release ACC which readily converts into ethylene (Davies and Zhang, 1991; Chen et al., 2013). Ethylene is a phytohormone, which performs dual role in plant development. Ethylene helps plant growth and development in the early stages, while the high concentration of ethylene directly inhibits root growth (Wang et al., 2002; Wilkinson and Davies, 2010). The impaired root system cannot get adequate water for plant growth and therefore reduce the yields (Bangash et al., 2013; Glick, 2014).

In order to combat drought effects, plants use multiple strategies such as change in gas exchange and water relation (Liu et al., 2005). Plant rhizosphere is usually known as a value added region for the beneficial microflora. The rhizosphere is typically rich in specific PGPR containing ACC deaminase enzyme (ACCd), which hydrolyzes ACC (ethylene precursor) and use it as the source of carbon and nitrogen (Honma and Shimomura, 1978; Belimov et al., 2005; Glick, 2014). Bacteria adhere to the plant roots and continuously break ACC in root exudates into ammonium

To cite this paper: Saleem, A.R., N. Bangash, T. Mahmood, A. Khalid, M. Centritto and M.T. Siddique, 2015. Rhizobacteria capable of producing ACC deaminase promote growth of velvet bean (Mucuna pruriens) under water stress condition. Int. J. Agric. Biol., 17: 663-667 
and $\alpha$-ketobutyrate until a dynamic equilibrium between the roots and rhizosphere bacteria is maintained. Rhizobacteria reduce the concentration of ACC resulting in reduced production of ethylene (Nadeem et al., 2013). The manipulation of bacterial community in the rhizosphere could possibly provide an economical and environment friendly way to improve crop yield by modulating the root system and functioning under low water conditions. For this purpose, rhizobacteria were isolated from the rhizosphere of velvet bean and screened for ACC deaminase activity. The selected strains of rhizobacteria were examined for their ability to promote growth of velvet bean in water stress conditions.

\section{Materials and Methods}

\section{Soil Sampling and Isolation of Rhizobacteria with ACCd Activity}

Rhizobacteria with ACCd activity were isolated from the rhizosphere of velvet bean. Velvet bean is not grown commonly in Pakistan, therefore soil samples were collected in polythene bags from different places (Haripur, Rawalpindi, Attock and Bahawalpur districts) to be used for growing velvet bean under control conditions. Velvet bean seeds were sown in small pots filled with different types of soil $(200 \mathrm{~g})$ separately. The pots were incubated at $25^{\circ} \mathrm{C}$. After $60 \mathrm{~d}$, plants were uprooted and non-rhizosphere soil was removed by gentle shaking. Roots with rhizosphere soil were stirred in sterile distilled water under aseptic conditions. This suspension was used for isolation of rhizobacteria through the dilution plate technique. About $250 \mu \mathrm{L}$ of the soil suspension from each dilution were placed on agar medium (Glick et al., 1994). ACC (50 $\left.\mathrm{mg} \mathrm{L}^{-1}\right)$ was used as the sole nitrogen source. Petri plates were incubated at $30^{\circ} \mathrm{C}$ for $48 \mathrm{~h}$. Initially 253 rhizobacterial isolates were selected and examined again in growth medium spiked with the ACC. After $48 \mathrm{~h}$ of incubation, the optical density (OD) of the bacterial cultures was checked at $600 \mathrm{~nm}$ with a UV visible spectrophotometer. Thirty rhizobacteria showing the highest growth (OD) were selected to evaluate their potential to promote growth of velvet bean.

\section{Effect of Rhizobacteria on Growth of Velvet Bean}

A petri dish experiment was performed to determine the effect of inoculation with ACCd active rhizobacteria on root growth of velvet bean. Velvet bean seeds were surface disinfected by soaking seeds in a solution of $95 \%$ ethanol for $20 \mathrm{sec}$, following a soak in $0.2 \%(\mathrm{w} / \mathrm{v}) \mathrm{HgCl}_{2}$ solution for $30 \mathrm{sec}$. Then, the seeds were rinsed with distilled sterilized water thoroughly to remove the seed disinfectant (Khalid et al., 2004). Selected isolates were grown in liquid medium containing ACC for $48 \mathrm{~h}$ at $30^{\circ} \mathrm{C}$. The sterilized seeds were then inoculated by soaking them in respective broth culture (OD $0.6 \pm 0.02$ at $600 \mathrm{~nm}$ ) of 30 selected rhizobacteria for $10 \mathrm{~min}$. In case of control treatment, the seeds were dipped in the un-inoculated medium. The inoculated seeds were placed between two sterilized Whatman filter paper sheets. Five (5) $\mathrm{mL}$ of sterilized distilled water was also used to wet filter paper sheets. The plates were placed in the growth incubator at $25 \pm 1^{\circ} \mathrm{C}$ for 10 d. The experiment was conducted in a completely randomized design with three replications. At the end of experiment, the data relating to root growth parameters was recorded.

Based on the results recorded for root growth, 10 effective isolates were selected to test their potential for promoting growth in glass jars. Velvet bean seeds were disinfected as described above. These seeds were placed on two filter paper sheets in a petri dish. Fifteen seeds were placed on each plate. The plates were incubated at $25 \pm 1^{\circ} \mathrm{C}$ for germination. Pre-germinated velvet bean seeds were inoculated by immersing in the respective inocula (OD $0.6 \pm 0.02$ at $600 \mathrm{~nm}$ ) and planted in glass jars containing 200 $\mathrm{g}$ of sterilized sand. For control, the seeds were immersed in sterilized medium. The jars with six replicates were placed in a growth chamber at $25 \pm 1^{\circ} \mathrm{C}$ in a completely randomized design. In addition, five $\mathrm{mL}$ of half strength Hoagland solution (Hoagland and Arnon, 1950) was added to each jar. After $20 \mathrm{~d}$, the plants were harvested and data on root length, dry root weight, shoot length and dry shoot weight were recorded.

\section{Effect of Selected Rhizobacteria on Growth of Velvet Bean under Water Stress}

Based on the rhizobacterial performance to improve root growth in the jar experiment five isolates (G4, G9, H6, H38 and HS9) were selected to evaluate their ability to promote plant growth in water deficit condition. The seeds germinated with uniform size were planted in soil (jar experiment). The water level was maintained at $45 \%$ of the water holding capacity (WHC) by weighing the pots and the addition of water based on the weight loss. However, weight gain due to the growth of plants was ignored. Seedlings were inoculated after two days by injecting $10 \mathrm{~mL}$ of inoculum. For control, autoclaved liquid medium was used. The experiment was performed with three replications. After 30 days, root length, shoot length, root dry weight and shoot dry weight were recorded.

\section{Classical Triple Response Bioassay}

To confirm the ACC-deaminase activity of selected rhizobacteria, classical triple response bioassay was performed with pea seeds (Shaharoona et al., 2006). Two pea seeds were positioned in the folds of sterile filter papers and placed in jar covered with green foil to give the green light. ACC at $5 \mathrm{mM}$ was used for seed treatment. All treatments were replicated three times. The jars were kept at $25 \pm 1^{\circ} \mathrm{C}$ in the dark. After 10 days, the classical "triple" response was observed by measuring the length and diameter of the seedlings. 


\section{Statistical Analysis}

The collected data were analyzed statistically using Statistx version 9.0 and LSD post hoc test.

\section{Results}

A total of 253 isolates were obtained from the rhizosphere of velvet bean. About $56 \%$ rhizobacteria had the ability to use ACC as the sole nitrogen source (Table 1). However, the bacterial biomass (OD) in a liquid medium varied from strain to strain. The maximum numbers of rhizobacteria with better growth in a medium of ACC were obtained from soil of Haripur district. Overall, 32\% rhizobacteria (47 out of 147) showed higher growth (OD>0.60) in a liquid medium containing ACC as a nitrogen source, while other isolates exhibited slow growth rate.

The results of root growth (Plate experiment) showed that inoculation with rhizobacteria significantly improved root length of velvet bean compared to uninoculated control (Table 2). The highest mean root length was observed in the case of inoculation with the isolate HS9 (isolated from Haripur soil). Inoculation with different rhizobacteria had a positive effect on root dry weight. Isolate HS9 was also effective in improving the root dry weight of velvet bean plants and showed the highest average root dry weight among the tested isolates. Similarly, more lateral roots were recorded in the case of inoculation with HS9. Some other isolates (A45, BS10, G9, H6) also had a positive effect on the development of lateral roots compared to uninoculated seedlings. A negative effect of inoculation with F32 isolate on the lateral roots was observed.

The selected isolates also improved root length up to $52.4 \%$ compared to the uninoculated control (Fig. 1a). Maximum root length was observed in plants inoculated with HS9 isolate. The increase in shoot length in response to inoculation was $64.6 \%$ compared with uninoculated plants (Fig. 1b). Rhizobacterial isolate G9 was the more efficient to increase the shoot length compared with uninoculated plants. Three other isolates (BS10, H6 and H38) also improved the root and shoot length compared to uninoculated control. Maximum increase in root dry weight was observed in the case of inoculation with isolate G9, G28 and HS9 (Fig. 1c) and the increase was $85.7 \%$ over the control. Other tested isolates were found also effective in improving the root dry weight compared to the control. The results showed that shoot dry weight in the case of inoculation with rhizobacteria was $56.5 \%$ greater than uninoculated control (Fig. 1d). The most promising shoot dry weight ( $0.36 \mathrm{~g}$ pr plant) was recorded in case of H38 inoculation compared to control.

Five selected isolates (G4, G9, H6, H38 and HS9) were evaluated for their potential to promote growth of velvet bean under water stress conditions. Velvet bean plants were grown to $45 \%$ of the water holding capacity (WHC). Maximum root length was observed in case of
Tab1e 1: Isolation of rhizobacteria producing ACCdeaminase from rhizosphere of velvet bean (Mисuna prurien L.)

\begin{tabular}{lllll}
\hline Sites & $\begin{array}{l}\text { Soil sample } \\
\text { code }\end{array}$ & $\begin{array}{l}\text { Total } \\
\text { isolates }\end{array}$ & $\begin{array}{l}\text { ACC active } \\
\text { isolates }\end{array}$ & $\begin{array}{l}\text { Isolates having OD } \\
\text { in }(>0.6 \text { at } 600 \mathrm{~nm})\end{array}$ \\
\hline Bahawalpur & B & 57 & 27 & 8 \\
Faisalabad & F & 45 & 16 & 7 \\
Rawalpindi & G & 72 & 45 & 13 \\
Haripur & H & 79 & 54 & 19 \\
\hline
\end{tabular}

Table 2: Effect of rhizobacteria containing ACCdeaminase on the seed root growth of velvet bean

\begin{tabular}{llll}
\hline Isolate & Root length $(\mathrm{cm})$ & Number of lateral root & $\begin{array}{l}\text { Root weight } \\
\text { (g per plant) }\end{array}$ \\
\hline Control & $2.10 \pm 0.22$ & $3 \pm 0.20$ & $0.006 \pm 0.003$ \\
A18 & $3.69 \pm 0.26$ & $3 \pm 0.17$ & $0.017 \pm 0.002$ \\
A16 & $1.94 \pm 0.25$ & $2 \pm 0.20$ & $0.007 \pm 0.004$ \\
A45 & $3.33 \pm 0.32$ & $4 \pm 0.21$ & $0.022 \pm 0.003$ \\
BS10 & $2.95 \pm 0.28$ & $4 \pm 0.22$ & $0.024 \pm 0.001$ \\
B12 & $2.20 \pm 0.14$ & $3 \pm 0.15$ & $0.012 \pm 0.001$ \\
B32 & $2.34 \pm 0.16$ & $3 \pm 0.22$ & $0.020 \pm 0.002$ \\
F16 & $2.51 \pm 0.22$ & $4 \pm 0.25$ & $0.020 \pm 0.002$ \\
F32 & $3.63 \pm 0.32$ & $2 \pm 0.17$ & $0.032 \pm 0.005$ \\
G4 & $4.25 \pm 0.33$ & $3 \pm 0.15$ & $0.043 \pm 0.005$ \\
G9 & $4.55 \pm 0.44$ & $4 \pm 0.15$ & $0.05 \pm 0.001$ \\
G28 & $2.45 \pm 0.27$ & $3 \pm 0.04$ & $0.019 \pm 0.00$ \\
H6 & $3.95 \pm 0.25$ & $4 \pm 0.13$ & $0.013 \pm 0.002$ \\
H17 & $3.28 \pm 0.22$ & $3 \pm 0.02$ & $0.02 \pm 0.003$ \\
H38 & $4.64 \pm 0.38$ & $3 \pm 0.21$ & $0.02 \pm 0.004$ \\
HS9 & $4.85 \pm 0.32$ & $5 \pm 0.16$ & $0.069 \pm 0.003$ \\
\hline
\end{tabular}

Table 3: Effect of rhizobacteria containing ACCdeaminase on the plant growth of velvet bean under water stress conditions

\begin{tabular}{lllll}
\hline Isolate & $\begin{array}{l}\text { Root length } \\
(\mathrm{cm})\end{array}$ & $\begin{array}{l}\text { Root weight } \\
(\mathrm{g} \text { per plant })\end{array}$ & $\begin{array}{l}\text { Shoot length } \\
(\mathrm{cm})\end{array}$ & $\begin{array}{l}\text { Shoot weight } \\
(\mathrm{g} \text { per plant })\end{array}$ \\
\hline Control & $18.17 \pm 1.7^{\mathrm{a}}$ & $0.20 \pm 0.1^{\mathrm{a}}$ & $31.83 \pm 4.4^{\mathrm{a}}$ & $0.50 \pm 0.1^{\mathrm{a}}$ \\
G4 & $21.83 \pm 0.9^{\mathrm{b}}$ & $0.29 \pm 0.1^{\mathrm{bc}}$ & $63.67 \pm 4.4^{\mathrm{b}}$ & $0.67 \pm 0.2^{\mathrm{b}}$ \\
G9 & $23.20 \pm 1.4^{\mathrm{bc}}$ & $0.30 \pm 0.1^{\mathrm{c}}$ & $62.33 \pm 3.4^{\mathrm{b}}$ & $0.77 \pm 0.1^{\mathrm{cd}}$ \\
H6 & $22.83 \pm 1.1^{\mathrm{b}}$ & $0.28 \pm 0.0^{\mathrm{b}}$ & $62.00 \pm 2.9^{\mathrm{b}}$ & $0.73 \pm 0.1^{\mathrm{c}}$ \\
H38 & $24.00 \pm 1.5^{\mathrm{c}}$ & $0.26 \pm 0.1^{\mathrm{b}}$ & $62.33 \pm 1.4^{\mathrm{b}}$ & $0.73 \pm 0.1^{\mathrm{c}}$ \\
HS9 & $23.50 \pm 1.2^{\mathrm{bc}}$ & $0.30 \pm 0.1^{\mathrm{c}}$ & $66.83 \pm 2.5^{\mathrm{c}}$ & $0.80 \pm 0.1^{\mathrm{d}}$ \\
\hline
\end{tabular}

inoculation with isolate $\mathrm{H} 38$, which was $32.1 \%$ greater than uninoculated plants (Table 3). Likewise, HS9 and G9 showed a significantly higher root length than control. Rhizobacterial isolates HS9 and G9 had a positive effect on the root dry weight and up to $50 \%$ more root weight was observed compared to uninoculated control. Similarly, shoot length under water stress also improved in response to inoculation with selected rhizobacterial isolates. Shoot length was $110 \%$ higher for inoculation with isolate HS9 than uninoculated control. Other selected isolates also exhibited promising effect on shoot length of velvet bean plants. An increase of $60 \%$ in shoot dry weight was recorded upon inoculation with isolate HS9 compared to the control. In general, all isolates tested had a positive effect on the shoot weight compared to uninoculated control. 
Table 4: Classical "triple" response of etiolated pea seedlings at different ACC concentrations (mM)

\begin{tabular}{llll}
\hline $\begin{array}{l}\text { ACC } \\
\text { concentrations }\end{array}$ & Shoot length $(\mathrm{cm})$ & Shoot diameter $(\mathrm{cm})$ & Root length $(\mathrm{cm})$ \\
\hline No ACC & $5.11 \mathrm{a}$ & $0.53 \mathrm{~d}$ & $5.33 \mathrm{a}$ \\
$2 \mathrm{mM}$ & $4.12 \mathrm{~b}$ & $1.03 \mathrm{c}$ & $3.48 \mathrm{~b}$ \\
$4 \mathrm{mM}$ & $3.14 \mathrm{c}$ & $1.74 \mathrm{~b}$ & $3.88 \mathrm{~b}$ \\
$6 \mathrm{mM}$ & $1.13 \mathrm{~d}$ & $2.09 \mathrm{a}$ & $3.30 \mathrm{c}$ \\
\hline
\end{tabular}

Table 5: Comparative effect of ACCd active rhizobacterial inoculation on etiolated pea seedlings in the presence of 5 $\mathrm{mM}$ ACC

\begin{tabular}{llll}
\hline 5 mM ACC & Shoot length $(\mathrm{cm})$ & Shoot diameter $(\mathrm{cm})$ & Root length $(\mathrm{cm})$ \\
\hline ACC only & $1.40 \mathrm{~d}$ & $1.99 \mathrm{a}$ & $1.08 \mathrm{~d}$ \\
ACC + G4 & $1.60 \mathrm{c}$ & $0.60 \mathrm{c}$ & $1.92 \mathrm{~b}$ \\
ACC + G9 & $1.57 \mathrm{c}$ & $0.80 \mathrm{~b}$ & $1.75 \mathrm{c}$ \\
ACC + H6 & $1.68 \mathrm{bc}$ & $0.77 \mathrm{~b}$ & $1.93 \mathrm{~b}$ \\
ACC + H38 & $1.77 \mathrm{ab}$ & $0.57 \mathrm{~cd}$ & $2.0 \mathrm{ab}$ \\
ACC + HS9 & $1.85 \mathrm{a}$ & $0.51 \mathrm{~d}$ & $2.17 \mathrm{a}$ \\
\hline
\end{tabular}
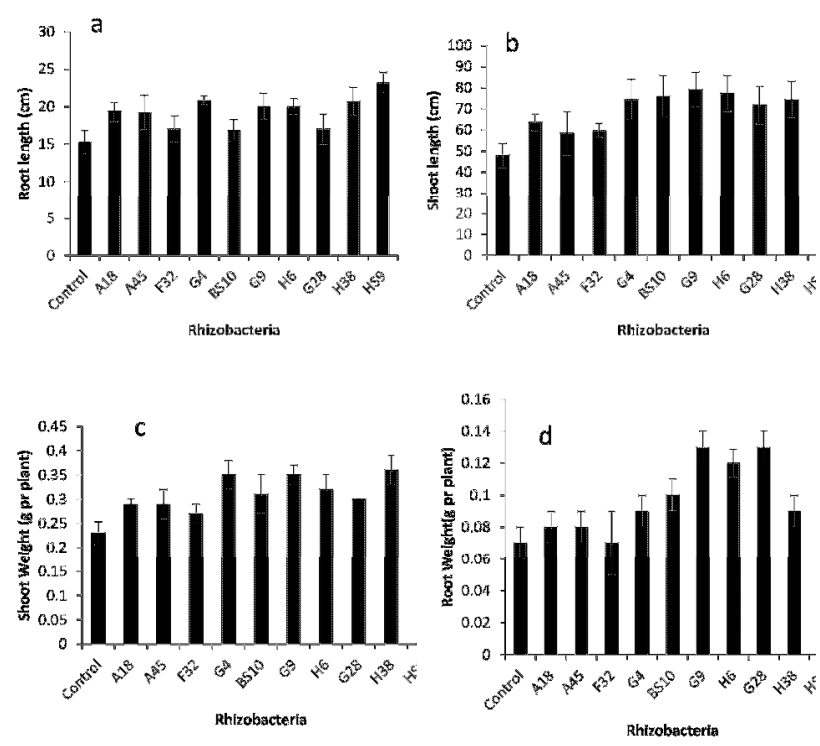

Fig. 1: Inoculation effect of ACC deaminase producing rhizobacteria on (a) root length, (b) shoot length, (c) dry root weight and (d) dry shoot weight of velvet bean seedlings in jar trial under control conditions

ACC-deaminase activity was confirmed by performing classical triple response bioassay (Table 4). The results revealed that the diameter of etiolated pea seedlings exposed to ACC increased considerably with increase in the concentration of ACC, while the length of the seedlings was reduced compared to the untreated control. Increased stem diameter and decrease in length of the seedlings was 74 and $77 \%$, respectively over the untreated control. However, inoculation of seedlings exposed to ACC diluted the effect of ACC and caused $32 \%$ increase in shoot length and $280 \%$ decrease in shoot diameter of etiolated pea seedlings.

\section{Discussion}

Rhizosphere soil was collected from different areas of Pakistan and used for isolation of ACCd active rhizobacteria. About $56 \%$ of the isolates were able to use ACC as a nitrogen source and grow in a medium enriched with ACC. However, rhizobacterial isolates showed substantial differences in growth potential in term of biomass. It has been reported that the bacteria isolated from rhizosphere soil of different crops have ACC deaminase enzyme that degrades available ACC (Glick et al., 2007; Shaharoona et al., 2008; Siddikee et al., 2011; Shahzad et al., 2013). The bacteria isolated from different locations can also vary in their genetic composition and enzymatic activities involved in the cleavage of ACC (Bangash et al., 2013). Probably for this reason rhizobacteria isolated from different locations had different effects on root growth of velvet bean plants. In general, the rhizobacteria with ACC deaminase activity showed a considerable improvement in the growth of roots compared with the uninoculated plants. ACCd active rhizobacteria possibly enhanced the root growth by reducing ethylene levels in the rhizosphere of velvet bean plant. It is widely known that PGPR hydrolyze ethylene precursor ACC, resulting in increased root growth (Belimov et al., 2001; Mayak et al., 2004; Shaharoona et al., 2006; Chen et al., 2013). The above findings are also supported by the results of the experiment under water stress condition. A significant improvement in the root and shoot growth was observed in plants inoculated with ACCd active bacteria compared to uninoculated plants. The rhizobacteria isolated from rainfed area (water stress) of Haripur district were more effective than other isolates. Ethylene is primarily known as a plant stress hormone (Arshad et al., 2008). It is synthesized in higher concentrations in plants under stress conditions and inhibits the root growth. The rhizobacteria with ACCd enzyme lower ethylene synthesis and thus inhibitory effects on plants are reduced (Kang et al., 2010; Shahzad et al., 2010). The results show that rhizobacteria having ACCd could be effective to stimulate growth of velvet bean.

In addition, ACCd activity of selected rhizobacteria was confirmed by classical triple response of etiolated pea seedlings. Pea seeds are very sensitive to the high concentration of ethylene and exhibits typical responses (increased diameter and reduced length of seedlings) (Shahroona et al., 2006). Inoculation with rhizobacteria containing ACC deaminase decreased the severity of ACCinduced classic response in etiolated pea seedlings. Furthermore, improvement in the length of the seedlings and root development implies that the negative effect of $\mathrm{ACC}$ can be reduced by inoculation with bacteria containing ACCd enzyme.

\section{Conclusion}

Rhizobacteria with ACCd significantly improved the plant growth, especially the root development of velvet beans. 
The improved root growth was possibly due to the ability of rhizobacteria to regulate ethylene levels in the rhizosphere. Best root system resulted in the promotion of shoot growth through increased supply of nutrients and water to the plant. The use of rhizobacteria containing ACCd is an environment friendly approach to increase agricultural productivity under stress condition.

\section{Acknowledgements}

Authors acknowledge the financial support from Higher Education Commission (HEC), Islamabad, under the Indigenous Ph.D. Fellowship program and the Ministero dell'Istruzione dell'Università e della Ricerca of Italy: PRIN 2010-2011 "PRO-ROOT" and Progetto Premiale 2012 "Aqua".

\section{References}

Arshad, M., B. Shaharoona and T. Mahmood, 2008. Inoculation with Pseudomonas spp. containing ACC-deaminase partially eliminates the effects of drought stress on growth, yield, and ripening of pea (Pisum sativum L.). Pedosphere, 18: 611-620

Bangash, N., A. Khalid, T. Mahmood and M.T. Siddique, 2013. Screening rhizobacteria containing ACC-deaminase for growth promotion of wheat under water stress. Pak. J. Bot., 45: 91-96

Barnaba, S.B., K. Jäger and A. Feher, 2008. The effect of drought and heat stress on reproductive processes in cereals. Plant Cell Environ., 31: $11-38$

Bates, B.C., Z.W. Kundzewicz, S. Wu and J.P. Palutikof, 2008. Climate change and water. Available at: http://ipcc.ch/pdf/technicalpapers/climate-change-water-en.pdf (Accessed: 22 December 2014)

Belimov, A.A., I.C. Dodd, N. Hontzeas, J.C. Theobald, V.I. Safronova and W.J. Davies, 2008. Rhizosphere bacteria containing 1aminocyclopropane-1-carboxylate deaminase increase yield of plants grown in drying soil via both local and systemic hormone signaling. New Phytol., 181: 413-423

Belimov, A.A., N. Hontzeas, V.I. Safronova, S.V. Demchinskaya, G. Piluzza, S. Bullitta and B.R. Glick, 2005. Cadmium-tolerant plant growth-promoting bacteria associated with the roots of Indian mustard (Brassica juncea L.). Soil Biol. Biochem., 37: 241-250

Belimov, A.A., V.I. Safronova, T.A. Sergeyeva, T.N. Egorova, V.A. Matveyeva, V.E. Tsyganov, A.Y. Borisov, I.A. Tikhonovich, C Kluge, A. Preisfeld, K.J. Dietz and V.V Stepanok, 2001 Characterization of plant growth-promoting rhizobacteria isolated from polluted soils and containing 1-aminocyclopropane-1carboxylate deaminase. Can. J. Microbiol., 47: 642-652

Centritto, M., M. Lauteri, M.C. Monteverdi and R. Serraj, 2009. Leaf gas exchange, carbon isotope discrimination, and grain yield in contrasting rice genotypes subjected to water deficits during the reproductive stage. J. Exp. Bot., 60: 2325-2339

Chaves, M., J. Flexas and C. Pinheiro, 2009. Photosynthesis under drought and salt stress: regulation mechanisms from whole plant to cell. Ann Bot., 103: 551-560

Chen, I., I.C. Dodd, W.J. Davies and S. Wilkinson, 2013. Ethylene limits abscisic acid- or soil drying-induced stomatal closure in aged wheat leaves. Plant Cell Environ., 36: 1850-1859

Davies, W. and J. Zhang, 1991. Root signals and the regulation of growth and development of plants in drying soil. Ann. Rev. Plant Physiol. Plant Mol. Biol., 42: 55-76

Grierson, C.S., S.R. Barnes, M.W. Chase, M. Clarke, D. Grierson, K.J. Edwards, G.J., Jellis, J.D. Jones, S. Knapp, G. Oldroyd, G. Poppy, P. Temple, R. Williams and R. Bastow, 2011. One hundred important questions facing plant science research. New Phytol., 192: 6-12

Ghanem, M., E.I. Hichri, A.C. Smigocki, A. Albacete, M.L. Fauconnier, E. Diatloff, C. Martinez-Andujar, S. Lutts, I.C. Dodd and Perez-Alfocea, 2011. Root-targeted biotechnology to mediate hormonal signalling and improve crop stress tolerance. Plant Cell Rep., 30: 807-823
Glick, B.R., 2014. Bacteria with ACC deaminase can promote plant growth and help to feed the world. Microbiol. Res., 169: 30-39

Glick, B.R., Z. Cheng, J.C. Czarny and J. Duan, 2007. Promotion of plant growth by ACC-deaminase containing soil bacteria. Eur. J. Plant Pathol., 119: 329-339

Glick, B.R., C.B. Jacobson, M.M.K. Schwarze and J.J. Pasternak, 1994. 1Aminocyclo propane-1-carboxylic acid deaminase mutants of the plant growth promoting rhizobacterium Pseudomonas putida GR122 do not stimulate canola root elongation. Can. J. Microbiol., 40: 911-915

Hoagland, D.R. and D. Arnon. 1950. The Water Culture Methods for Growing Plants Without Soil, p: 39. Circular No. 347, Davis California Agriculture Experiment Station, California, USA

Honma, M. and T. Shimomura, 1978. Metabolism of 1-aminocyclopropane1-carboxylic acid. Agric. Biol. Chem., 42: 1825-1831

IPCC, 2007. Impacts, Adaptation and Vulnerability. Cambridge University Press, United Kingdom

Kang, B.G., W.T. Kim, H.S. Yun and S.C. Chang, 2010. Use of plant growth-promoting rhizobacteria to control stress responses of plant roots. Plant Biotechnol., 4: 179-183

Khalid, A., M. Arshad and Z.A. Zahir, 2004. Screening plant growthpromoting rhizobacteria for improving growth and yield of wheat. $J$. Appl. Microbiol., 96: 473-480

Lauteri, M., M. Haworth, R. Serraj, M.C. Monteverdi and M. Centritto, 2014. Photosynthetic diffusional constraints affect yield in drought stressed rice cultivars during flowering. Plos One, 9: e109054

Liu, F.L., C.R. Jensen and M.N. Andersen, 2005. A review of drought adaptation in crop plants: changes in vegetative and reproductive physiology induced by ABA-based chemical signals. Aust. J. Agric. Resour., 56: 1245-1252

Lynch, J.P., 2007. Roots of the second green revolution. Aust. J. Bot., 55: 493-512

Mayak, S., T. Tirosh and B.R. Glick, 2004. Plant growth-promoting bacteria that confer resistance to water stress in tomatoes and peppers. Plant Sci. 166: 525-530

Nadeem, S.M., Z.A. Zahir, M. Naveed and M. Ashraf, 2013. Microbial ACC-deaminase: prospects and applications for inducing salt tolerance in plants. Crit. Rev. Plant Sci., 29: 360-393

Ren, J., W. Dai, Z. Xuan, Y. Yao, H. Korpelainen and C. Li, 2007. The effect of drought and enhanced UV-B radiation on the growth and physiological traits of two contrasting poplar species. For. Ecol. Manage., 239: 112-119

Shaharoona, B., M. Naveed, M. Arshad and Z.A. Zahir, 2008. Fertilizer dependent efficiency of Pseudomonads containing ACC-deaminase for improving growth, yield and nutrient use efficiency of wheat (Triticum aestivum L.). Appl. Microbiol. Biotechnol., 79: 147-155

Shaharoona, B., M. Arshad and Z.A. Zahir, 2006. Effect of plant growth promoting rhizobacteria containing ACC deaminase on maize (Zea mays L.) growth under axenic conditions and on nodulation in mung bean (Vigna radiata L.). Lett. Appl. Microbiol., 42: 155-159

Shahzad, S.M., A. Khalid, M. Arshad, J. Tahir and T. Mahmood, 2010 Improving nodulation, growth and yield of Cicer arietinum L. through bacterial ACC-deaminase induced changes in root architecture. Eur. J. Soil Biol., 46: 342-347

Shahzad, S.M., M.S. Arif, M. Riaz, Z. Iqbal and M. Ashraf, 2013. PGPR with varied ACC-deaminase activity induced different growth and yield response in maize (Zea mays L.) under fertilized conditions. Eur. J. Soil Biol., 57: 27-34

Siddikee, M.A., B.R. Glick, P.S. Chauhan, W.J. Yim and T. Sa, 2011. Enhancement of growth and salt tolerance of red pepper seedlings (Capsicum annuиm L.) by regulating stress ethylene synthesis with halotolerant bacteria containing 1-aminocyclopropane-1-carboxylic acid deaminase activity. Plant Physiol. Biochem., 49: 427-434

Vacheron, J., G. Desbrosses, M.L. Bouffaud, B. Touraine, Y. MoënneLoccoz, D. Muller, L. Legendre, F. Wisniewski-Dyé and C.P. Combaret, 2013. Plant growth-promoting rhizobacteria and root system functioning. Front. Plant Sci., 4: 356-360

Wang K.L.C., H. Li and J.R. Ecker, 2002. Ethylene biosynthesis and signaling networks. Plant Cell, 14: 131-151

Wilkinson, S. and J.W. Davies, 2010. Drought, ozone, ABA and ethylene: new insights from cell to plant to community. Plant Cell Environ. 33: $510-525$

(Received 26 September 2014; Accepted 27 February 2015) 